\title{
The "loop" technique for primary spontaneous pneumothorax: a retrospective study of 18 patients
}

\author{
Giampiero Dolci ${ }^{1}$, Alessio Campisi ${ }^{1}$, Marco Trotta $^{1}$, Sara Mazzarra ${ }^{1}$, Stefano Congiu ${ }^{1}$, Luca Bertolaccini ${ }^{2}$, \\ Piergiorgio Solli ${ }^{2}$, Andrea Dell'Amore ${ }^{1}$
}

${ }^{1}$ Department of Cardiothoracic and Vascular Surgery, University Hospital S. Orsola Malpighi, Bologna, Italy; ${ }^{2}$ Department of Thoracic Surgery, AUSL Bologna Maggiore Teaching Hospital, Bologna, Italy

Contributions: (I) Conception and design: G Dolci; (II) Administrative support: A Dell'Amore, A Campisi, L Bertolaccini, P Solli; (III) Provision of study materials or patients: A Campisi; (IV) Collection and assembly of data: M Trotta, S Mazzarra, S Congiu, A Campisi; (V) Data analysis and interpretation: A Campisi; (VI) Manuscript writing: All authors; (VII) Final approval of manuscript: All authors.

Correspondence to: Alessio Campisi. Department of Cardiothoracic and Vascular Surgery, University Hospital S. Orsola Malpighi, Bologna, Italy.

Email: alessio.campisi@studio.unibo.it.

\begin{abstract}
Background: Primary spontaneous pneumothorax (PSP) is a well-known disease but with multiple different surgical approaches. The objective of our study is to present the results of an innovative minimal uniportal approach for patients with such a disease. This will be able to reduce postoperative pain simultaneously considering the cosmetic problems of otherwise 'healthy' patients.

Methods: We retrospectively evaluated the surgical results of 18 patients who underwent single incision thoracoscopic surgery (SITS) using a loop at our institution between January 2015 and August 2016. Single access of $20 \mathrm{~mm}$ was done at the level of the 8th intercostal space. We used a 'loop' of a non-absorbable braided suture inserted through the IV intercostal space to isolate and suspend any dystrophic area to resect. In every patient, the pulmonary ligament was dissected and pleurodesis done with pleural abrasion.

Results: We had no complications after SITS. The mean operative time for SITS was $55 \pm 7.36$ (standard deviation) minutes. Usually, the chest tube is removed in the 2 nd postoperative day, and the patient discharged the day after. There were no conversions from SITS to three-port VATS or thoracotomy. Nobody reported chronic pain and paraesthesia. No patients had an ipsilateral recurrence of pneumothorax in the 2 years after surgery.

Conclusions: The operation we propose is safe and easily reproducible. Considering the small number of patients, this technique offers excellent results regarding the duration of recovery, postoperative pain and paraesthesia, without increasing the risks of complications for the patient and the costs of surgery.
\end{abstract}

Keywords: Lung; pneumothorax; video-assisted thoracoscopic surgery (VATS); uniportal; primary spontaneous pneumothorax (PSP); loop technique

Received: 05 September 2018; Accepted: 10 December 2018; Published: 27 December 2018.

doi: $10.21037 /$ shc.2018.12.05

View this article at: http://dx.doi.org/10.21037/shc.2018.12.05

\section{Introduction}

Primary spontaneous pneumothorax (PSP) is a well-known disease usually affecting young healthy male patients. Nowadays, the gold standard surgical approach in case of non-complicated PSP is a video-assisted thoracoscopic surgery (VATS) using one or more ports (1).
In 1998, Yamamoto et al. (2) published the use of a single incision approach with a flexible bronchoscope as a camera with good results. Nevertheless, it was necessary to wait for 2004 when Rocco et al. (3) reported a technique for VATS wedge pulmonary resection through a single port, so single incision thoracoscopic surgery (SITS) started to be also used for pneumothorax. It has many advantages over 


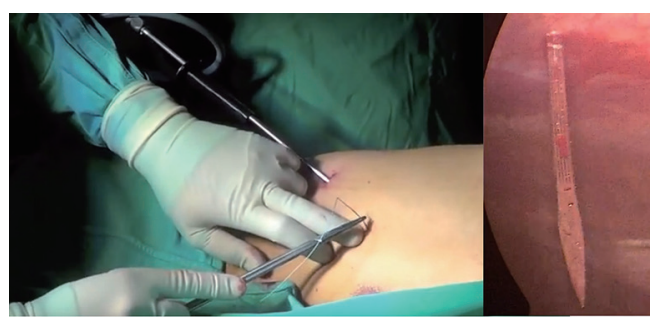

Figure 1 Surgical field and intraoperative camera showing the loop inserted through the IV intercostal space.

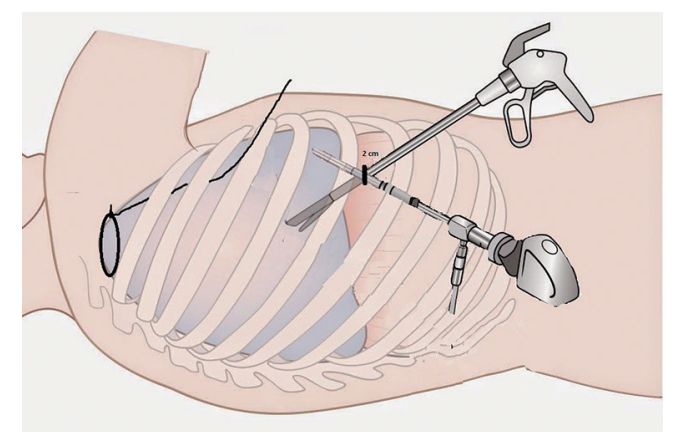

Figure 2 The "loop" technique, angulation of the instruments.

three-port VATS, such as lower postoperative pain, better cosmetic results etcetera $(4,5)$.

We started using SITS in 2012, but only in the last 2 years, we established a standard technique for patients with PSP (6). It requires single access of $20 \mathrm{~mm}$ at the level of the 8th intercostal space. Once introduced a $5 \mathrm{~mm}$ thoracoscope, the chest cavity is inspected to localise any bullae or dystrophic area of the lung parenchyma. For the isolation and suspension of these areas, we use a 'loop' of non-absorbable braided suture thread inserted through the IV intercostal space (Figure 1) with serial sectioning using a classic endoscopic $10 \mathrm{~mm}$ mechanical stapler (Figure 2). Thus, completed the resection, using caudal access to the chest cavity, it is possible to visualise and dissect the pulmonary ligament, in order to avoid a postoperative residual pleural space at the apex and to perform the pleurodesis based on the abrasion of the parietal pleura.

\section{Methods}

Between January 2015 and August 2016, 18 patients with PSP have been treated surgically using the new loop technique. Patients underwent SITS for the following indications: ipsilateral PSP recurrence (11/18 patients), persistent air leakage after chest tube drainage (3/18), contralateral PSP (4/18).

All the patients underwent the same technique, and there were no conversions from SITS to three-ports VATS or thoracotomy. The study was approved by institutional review board of University of Bologna, Alma Mater Studiorum and written informed consent was obtained from all patients.

The chest tube was removed after confirming the absence of air leakage. All patients were followed for at least a month after surgery. Chest $\mathrm{X}$-rays were performed 1 month after the operation or if necessary. Patients were surveyed for recurrence by direct phone communication 6 months and 2 years after surgery. A recurrence was defined as an ipsilateral pneumothorax demonstrated by radiological examinations.

We examined our database for clinical characteristics including age, sex, body mass index, the side involved, smoking status, surgical indications and surgical results such as operative time, surgical conversion, length of chest drainage, length of hospital stay, early complication, and recurrence. Postoperative pain was evaluated using the Visual Analogue Scale (VAS) (7), VAS 0 correspond with no pain, and VAS 10 is the worst pain imaginable (VAS range from 0 to 10). Nurses performed the patient's interview at postoperative day $0,1,2$ and the day of discharge. The results were annotated in the medical record of the patient.

\section{Results}

Demographics of the 18 patients are shown in Table 1. The mean age was $24.6 \pm 5.37$ years. All patients were male. The indications for surgery were ipsilateral recurrence in 11 cases, persistent air leakage in 3, contralateral recurrence in 4 . Thirteen patients were actually or previously smokers.

The surgical results are shown in Table 2. Mean operative time was $55 \pm 7.36$ minutes and it does not differ from our historical cases. There were no conversions to three-port VATS or thoracotomy from SITS. One to four mechanical staples (median of three staples) were used to excise the blebs and bullae; all patients had their bullae and blebs at the apex and lateral side of the upper lobe. We perform physical pleurodesis and section of the pulmonary ligament in every patient who undergoes surgery for pneumothorax, and so we did it with SITS. Chest drain suction at $-20 \mathrm{~cm} \mathrm{H} 2 \mathrm{O}$ was maintained for 48 hours with the digital draining system (Thopaz ${ }^{\mathrm{TM}}$, Medela Italia Srl). The chest tube was removed when the pleural effusion is lower than $400 \mathrm{~mL} /$ day 
Table 1 Clinical characteristics of 18 patients with PSP

\begin{tabular}{lc}
\hline Characteristics & Values \\
\hline Age, years (mean \pm SD) & $24.6 \pm 5.37$ \\
Sex & 18 \\
Male & 0 \\
Female & $22 \pm 3.36$ \\
BMI, kg/m ${ }^{2}$ (mean \pm SD) & \\
Side involved & 11 \\
Right & 7 \\
Left & \\
Smoking status & 5 \\
Never & 13 \\
Former or current & \\
Surgical indication & 11 \\
Recurrence & 3 \\
Persistent air leak $(>72$ hours) & 4 \\
Contralateral pneumothorax & 0 \\
Other & \\
\hline
\end{tabular}

PSP, primary spontaneous pneumothorax.

Table 2 Surgical results of 18 patients with PSP

\begin{tabular}{lc}
\hline Characteristics & Values \\
\hline Operative time, min (mean \pm SD) & $55 \pm 7.36$ \\
Median mechanical staplers used (mean \pm SD) & $3 \pm 0.96$ \\
Conversion to standard VATS/thoracotomy & 0 \\
Pleurodesis (brushing) & 18 \\
Section of the pulmonary ligament & 18 \\
Median postoperative drainage, days (mean \pm SD) & $2 \pm 0.60$ \\
Median postoperative stay, days (mean \pm SD) & $3 \pm 0.63$ \\
Postoperative pain (NRS)' (mean \pm SD) & \\
POD 0 & $1 \pm 1.23$ \\
POD 1 & $0 \pm 0.61$ \\
POD 2 & $0 \pm 0.32$ \\
Discharge & $0 \pm 0.23$ \\
Postoperative complications & None \\
Ipsilateral recurrence & None \\
\hline
\end{tabular}

POD, postoperative day; PSP, primary spontaneous pneumothorax. and air leak flow $<40 \mathrm{~mL} / \mathrm{min}$ for more than eight hours (and without spikes of airflow greater than this value) (8). The median duration of chest drainage was $2 \pm 0.60$ days. The patients were discharged the day after chest tube removal. We had no early or late complications.

Postoperative pain control was performed by e.v. injection of 1,000 $\mathrm{mg}$ paracetamol three times per day and three patients needed in the day of surgery an additional injection of a non-steroidal anti-inflammatory drug (30 mg ketorolac) because VAS scale was higher than 3 . Every patient was contacted at 6 and 24 months from surgery, no recurrent pneumothorax developed during this period and no chronic pain was reported.

The small number of patients limits our results. Nevertheless, we are allowed to say that our technique is an easy procedure to learn and perform in PSPs without increasing the risks of complications or recurrence for the patients.

\section{Conclusions}

Thoracic surgery is living a new era with the introduction of minimally invasive surgery, and SITS/U-VATS is, for sure, one of the most innovating procedure. In the last few years, especially for PSP, single port VATS is taking up space with a different type of procedure to perform lung resection without increasing the size of the incision (9-13).

Son et al. described anchoring suture technique for single port VATS wedge resection (11); Jeon and Kim (12) described a technique similar to ours but they pass the needle through the lung parenchyma that can be injured, and so it has needed another suture. Moreover, with our procedure, it is possible to reduce the amount of lung parenchyma to remove.

Our loop technique allows to perform SITS without increasing the cost of the operation because no other device is needed, the mean operative time is less than one hour, and it offers excellent results regarding the duration of recovery, postoperative pain and paraesthesia, without increasing the risks of complications for the patient. The access to the pulmonary ligament is comfortable, and the obliteration of the pleural space is simple performing abrasion. No patients suffered from chronic postoperative pain and no ipsilateral recurrence was diagnosed in the 24 postoperative months.

However, we intend to resubmit the data mentioned above after having studied a more numerous groups of patients that have undergone such surgery. 


\section{Acknowledgments}

Funding: None.

\section{Footnote}

Conflicts of Interest: All authors have completed the ICMJE uniform disclosure form (available at http://dx.doi. org/10.21037/shc.2018.12.05). LB serves as an unpaid editorial board member of Shanghai Chest from Jun 2017 to May 2019. The other authors have no conflicts of interest to declare.

Ethical Statement: The authors are accountable for all aspects of the work in ensuring that questions related to the accuracy or integrity of any part of the work are appropriately investigated and resolved. The study was conducted in accordance with the Declaration of Helsinki (as revised in 2013). The study was approved by institutional review board of University of Bologna, Alma Mater Studiorum and written informed consent was obtained from all patients.

Open Access Statement: This is an Open Access article distributed in accordance with the Creative Commons Attribution-NonCommercial-NoDerivs 4.0 International License (CC BY-NC-ND 4.0), which permits the noncommercial replication and distribution of the article with the strict proviso that no changes or edits are made and the original work is properly cited (including links to both the formal publication through the relevant DOI and the license). See: https://creativecommons.org/licenses/by-nc-nd/4.0/.

\section{References}

1. Treasure T. Minimally invasive surgery for pneumothorax: the evidence, changing practice and current opinion. J R Soc Med 2007;100:419-22.

2. Wu YW, Jian YP, Liang JS, et al. The treatment of intrahepatic calculosis by applying helix hydro-jet lithotripsy under video choledochoscope: a report of 30 cases. Langenbecks Arch Surg 2006;391:355-8.

3. Rocco G, Martin-Ucar A, Passera E. Uniportal VATS wedge pulmonary resections. Ann Thorac Surg 2004;77:726-8.

4. Jutley RS, Khalil MW, Rocco G. Uniportal vs standard three-port VATS technique for spontaneous pneumothorax: comparison of post-operative pain and residual paraesthesia. Eur J Cardiothorac Surg 2005;28:43-6.

5. Salati M, Brunelli A, Xiumè F, et al. Uniportal videoassisted thoracic surgery for primary spontaneous pneumothorax: clinical and economic analysis in comparison to the traditional approach. Interact Cardiovasc Thorac Surg 2008;7:63-6.

6. Campisi A, Dell'Amore A, Giunta D, et al. Microincision thoracoscopic treatment of primary spontaneous pneumothorax: the "loop" technique. J Vis Surg 2018;4:35.

7. Maguire MF, Ravenscroft A, Beggs D, et al. A questionnaire study investigating the prevalence of the neuropathic component of chronic pain after thoracic surgery. Eur J Cardiothorac Surg 2006;29:800-5.

8. Pompili C, Brunelli A, Salati M, et al. Impact of the learning curve in the use of a novel electronic chest drainage system after pulmonary lobectomy: a case-matched analysis on the duration of chest tube usage. Interact Cardiovasc Thorac Surg 2011;13:490-3; discussion 493.

9. Ichinose J, Nakahara K, Kina S, et al. One-port videoassisted thoracic surgery for pneumothorax using mini loop retractor. Kyobu Geka 2010;63:371-4.

10. Tsuboshima K, Matoba $Y$, Sato M, et al. Evaluation of 2 ports video-assisted thoracoscopic surgery (VATS) using endo-close for primary spontaneous pneumothorax. Kyobu Geka 2013;66:210-3.

11. Son BS, Kim DH, Lee SK, et al. Small Single-Incision Thoracoscopic Surgery Using an Anchoring Suture in Patients With Primary Spontaneous Pneumothorax: A Safe and Feasible Procedure. Ann Thorac Surg 2015;100:1224-9.

12. Jeon HW, Kim YD. Does $11.5 \mathrm{~mm}$ guided single port surgery has clinical advantage than multi-port thoracoscopic surgery in spontaneous pneumothorax? J Thorac Dis 2016;8:2924-30.

13. Tsuboshima K, Nagata M, Wakahara T, et al. Feasibility of single-incision thoracoscopic surgery using a modified chest wall pulley for primary spontaneous pneumothorax: a propensity score matching analysis. Surg Today 2017;47:1129-34.

doi: $10.21037 /$ shc.2018.12.05

Cite this article as: Dolci G, Campisi A, Trotta M, Mazzarra S, Congiu S, Bertolaccini L, Solli P, Dell'Amore A. The "loop" technique for primary spontaneous pneumothorax: a retrospective study of 18 patients. Shanghai Chest 2018;2:102. 